\title{
A STRUCTURED MODEL FOR PERFORMANCE ASSESSMENT IN PROPERTY MANAGEMENT
}

\section{Mohammed Kishk $^{1 *}$, Robert Pollock ${ }^{1}$, and Jummai Atta ${ }^{2}$}

${ }^{1}$ The Scott Sutherland School, The Robert Gordon University, Garthdee Road, Aberdeen $A B 107 Q B, U K$

${ }^{2}$ School of Engineering, The Robert Gordon University, Schoolhill, Aberdeen AB10 IFR, $U K$.

* Corresponding Author

E-mail: m.kishk@rgu.ac.uk

Tel: $\quad+44(0) 1224263710$

Fax: $\quad+44(0) 1224263777$ 
- There has been a dearth of material on property performance to aid property management practices. Besides, there is a seeming lack of structured processes for carrying out the performance measurement of properties.

- Basic characteristics of an effective performance assessment in property managements are identified and the framework for a generic model is outlined.

- The framework is built around key processes of performance measurement and property management tasks. These processes are then set out into steps for better understanding and applicability of the model to actual property management practices.

- Some unique features of the model include consideration of clients and tenants requirements, integration of the functions of property management in the model and the inclusion of a property and resource database to aid storage and retrieval of information.

Keywords: Facilities management, performance measurement, property management

\section{INTRODUCTION}

Although the concept of performance measurement is still relatively new in property management, building performance is increasingly considered these days. According to Douglas (1996), expectations, standards, and building requirements of occupiers have increased owing to advances in technology and changes in economic conditions. Besides, both occupiers and owners require their buildings to be attractive, enduring, comfortable, and cost-efficient. These intensified requirements have immensely increased the relative importance of property management in the success of property as an investment as pointed out by Downs (1991). These demands also require the property manager to 
effectively set out strategies for property management and to monitor the progress of the property in satisfying these demands.

Atta (2004) has concluded that there is an unawareness of the potential of performance measurement in satisfying the demands of both tenants and clients in most property management practices as only about a third of practices surveyed undertook performance measurement in a recognisable format using identified techniques. Besides, almost none of the respondents use a structured process or a computer programmes in managing information and the performance measurement process as a whole. According to Baird and Gray (1996), buildings are managed for short-term goals rather than medium or longterm. Besides, there is a dearth of information for property performance measurement and a lack of a structured process for property performance measurement. Amaratunga (2000) states that the growing acceptance of a need to measure performance is in contrast to a lack of systematic process for determining appropriate measurements.

The objective of the research work that underpins this paper is to outline a structured model to be used for property performance measurement. The rest of the paper is organised as follows. In the following section, the scope of property management is defined for the purpose of this research. Then, further requirements for effective performance assessment are identified. Next, the framework of a generic performance assessment model is outlined. Finally, the research work is summarised and directions for further research are introduced. For convenience of the reader, basic symbols used to outline the model are summarised in an appendix. 


\section{MANAGEMENT OF PROPERTY ASSETS}

Most of the published literature do not consider performance measurement of property from the established viewpoint of property management but are rather inclined towards facilities management and corporate real estate management. Although both concepts may be analogous to property management in the overall aim of securing optimum returns from property, they may differ in actual processes and structure (Atta, 2003). This will be highlighted in the following subsections in order to provide a better understanding of the scope of property management for the purpose of this study.

\section{Facilities Management}

Amaratunga and Baldry (2001) traced the origins of facilities management back to the early 1990s as buildings with their infrastructure and content become more sophisticated. Tay and Ooi (2001) conclude that its definition and scope remains a contentious issue and their evaluation of various definitions suggests that the focus is on the workplace. According to Becker (1989), it is fundamentally, responsible for the planning design and management of the total work environment of organisations. Greed et al (2000) who treat built asset management as being synonymous with facilities management states that maintenance and refurbishment, components of facilities management, are carried out to keep buildings and sites at an appropriate standard for the organisation in occupation.

\section{Corporate Real Estate Management}

Bon et al (1998) states that corporate real estate management concerns the management of buildings and parcels of land at the disposal of private and public organisations those 
are not primarily in the real estate business. This covers a range of activities concerning portfolios of buildings and land holdings: investment planning and management, financial planning and management, construction planning and management and facilities planning and management. This has however been coined as portfolio management by Scarrett (1995) and considered as the single management of a cohesive group of buildings where either freehold or leasehold interests are held by one client, usually organisations.

\section{Property Management}

Stansall (1994) has identified the core of property management by differentiating it from facilities management as being the valuation, acquisition and disposal of buildings, providing advice on property investments, the administration of leases, rental and service charges and the supervision of building repairs. Facilities management can be considered, however, an integral part of property management when viewed from the context of independent property managers of income producing properties. Here, its understanding is analogous to the corporate real estate management context as it involves running the property and not just services. However, this involves a day-to-day management rather than the strategic and long-term view as in corporate real estate management (Atta, 2003).

Property management as is being considered here aims to cover these range of activities but as an external advisor and agent of property owners and some of the activities may therefore not be applicable such as planning and managing moves for a company, furniture arrangement and other responsibilities specific to the company's business goals. 


\section{CRUCIAL REQUIREMENTS}

\section{Setting Objectives}

Dixon (1991) suggests that one needs to recognise that PIs are necessarily tied to strategy; as strategies change, performance measures must change to reflect those new strategies. Many researchers have proposed to identify/set the objectives for the property as instructed by the client or in line with the client requirements. It might be necessary prior to this to note the property characteristics if there have been any changes or if it is a new property. Most researchers have suggested that the requirements of the owner should be identified in initial stages of performance measurement. This is usually expressed in qualitative terms and there is a need to convert them to quantitative terms when the indicators are being set.

\section{Tenant Selection}

Because the performance measurement process is integrated into property management, it is necessary to include the stage of the tenant selection. This stage has been stressed in many performance measurement methods including the serviceability tools and methods (STM) (Davis and Szigeti, 1996) and the real estate norm (REN) (Jonge and Gray, 1996). The tenant selection process is a critical part of the management function as indicated in the literature review. As well as assessing the potential tenant's co-operation and rent paying ability, there is a need to identify the tenant's requirements for the property. The STM methodology can be employed here. Although the tenant is asked to specify general requirements in broad functional and physical categories, limits should be specified 
depending on the resources available at the manager's disposal for measurements when the requirements are converted to PIs (Atta, 2003).

\section{Setting Improvement Targets}

The establishment of considered improvement targets is a fundamental next step here and Varcoe (1996) has set out that comparable measures among other peer organisations can be sought to assist here. Sanger (1998) however indicates that in some cases it may be necessary to establish targets based on a range of acceptable performance or to measure actual performance against planned performance. He concludes further on that targets may be internally imposed or more preferably a benchmark from competitors. In property management practices though, this might be a challenge (Atta, 2003). Subsequently, the actual performance measurement is carried out and this process should stimulate action from the results of the measures and ensure a mechanism for reviewing and learning from the information measures provided (Bourne and Bourne, 2000).

\section{A FRAMEWORK FOR A GENERIC MODEL}

Based on the above arguments, the essential activities required for effective performance assessment can be effectively summarised as:

- Identifying property attributes.

- Identifying Client's requirements.

- Tenant selection for the property if the property is vacant, somewhat based on their requirements. 
- Transforming these requirements into relevant performance indicators for achieving the objectives.

- Actual measurement of these indicators.

- Comparison, identification of performance gaps and improvements.

These activities can be arranged in logical order to form the framework of a generic model for property performance measurement (figure 1). As shown, a resource database and a property database have been integrated into the model to aid the continuous review of performance and the management of other information specific or non-specific to the property in the property and resource database, respectively.

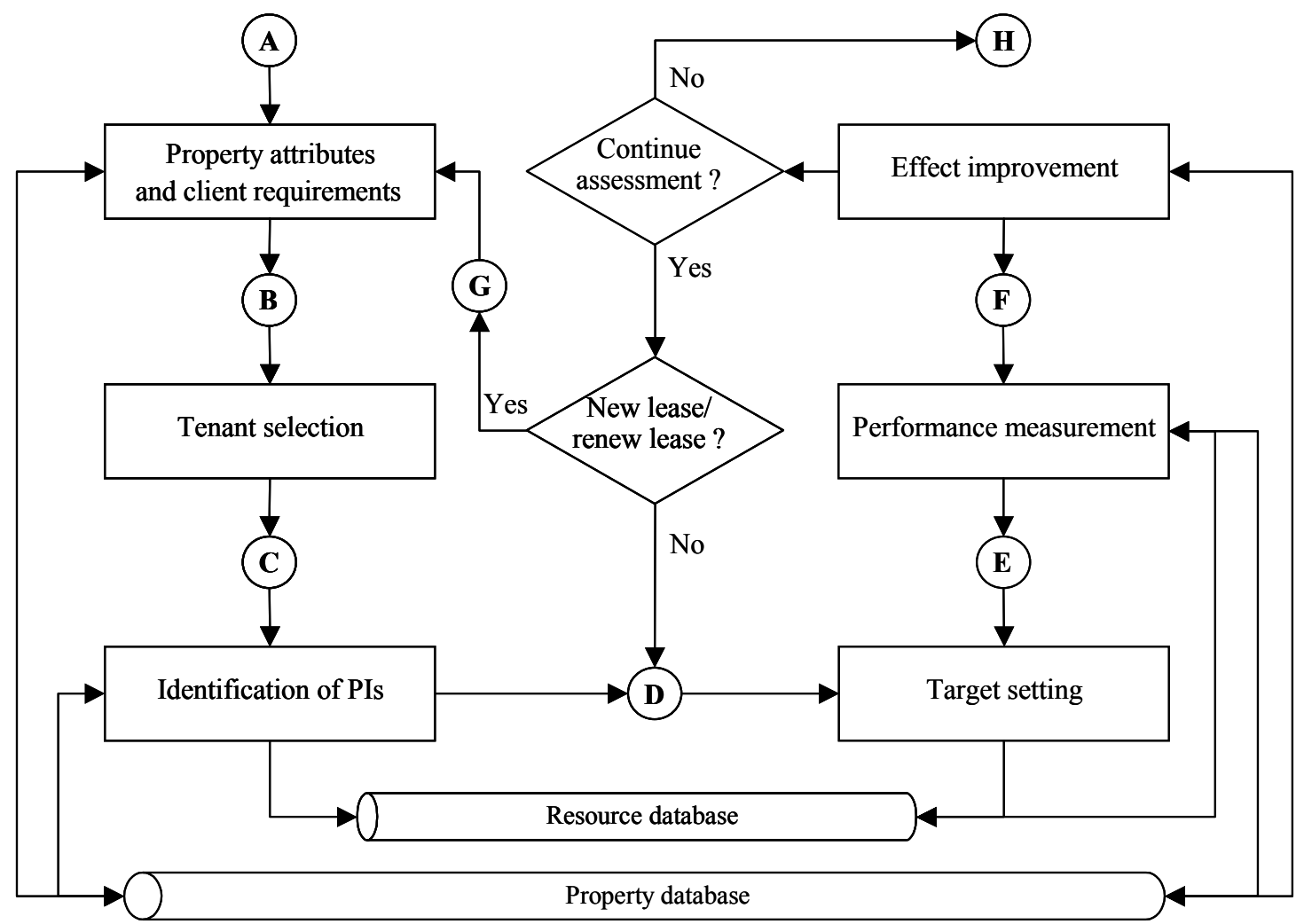

Figure 1: A simplified process flow diagram of the model framework 


\section{DETAILS DESIGN OF THE MODEL}

\section{Identifying Property Attributes and Client Requirements}

The first step in this phase involves an identification of the property attributes, for inclusion in the database, by a site inspection after the property has been received. These attributes would include such information as the type of property, the location, and accommodation details. This phase also requires an identification and review of the client's general requirements for further conversion into PIs and for consideration in setting targets. Following this, as required for property management practice, the manager has to carry out a demand appraisal where the property is to be leased or the lease is to be renewed so as to advise the client in setting property requirements and in the tenant selection phase for new leases. In analysing demands, the property manager has to consider recent trends and general market conditions and this information may be retrieved from the resource database.

If not, this information for demand analysis may need to be retrieved from a market survey and relevant information gotten there from stored in the resource database for other properties. There is a need to identify in the next step the client's requirements for the property. If there is no change in this step, the flow moves onto the next phase of tenant selection. Where, there is a change in clients' requirements, there would be a review of the requirements originally expressed by the client. The process flow diagram for this phase is shown in figure 2. 


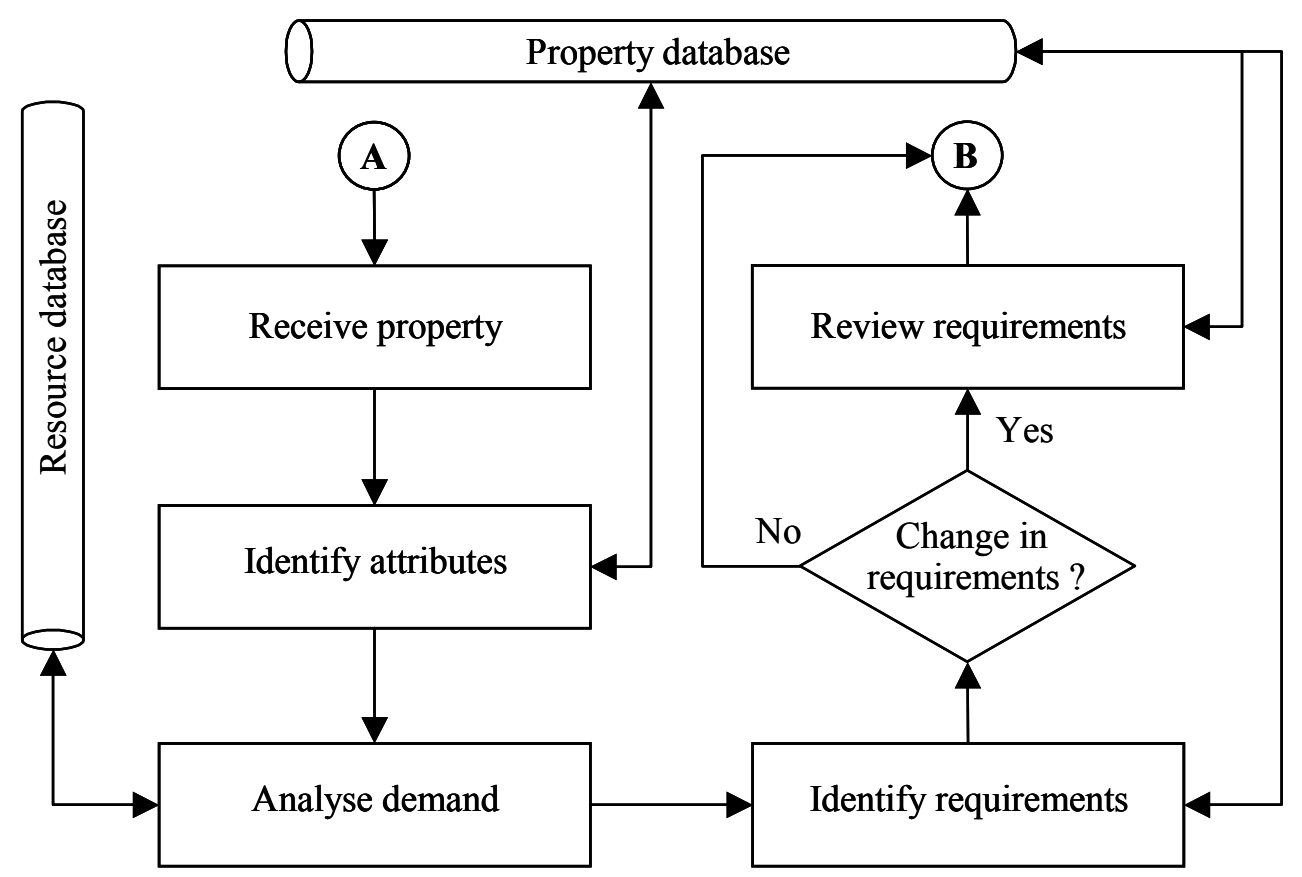

Figure 2: Simplified process flow diagram for the attributes and requirements stage

\section{Tenant Selection}

The tenant selection process is a critical part of the management function. As well as assessing the potential tenant's co-operation and rent paying ability, there is a need to identify the tenant's requirements for the property. The STM methodology of using questionnaires is proposed here. Limits should be specified depending on the resources available at the manager's disposal for measurements when the requirements are converted to PIs. Normally, statements stated at this stage will have to be developed by the property manager using multiple indicators that influence its overall satisfaction of this requirement. Besides, it will serve as records to be included in the lease agreement. If conflicts exist with client's requirements, a decision has to be made based on demands on the property, void periods, proposed length of lease and other factors regarding considering the tenant's requirements. If there is no possibility of client's requirements 
review and requirements are not agreeable to the tenant, other potential tenants would have to be considered.

Where there is a possibility however and this is done, it would then be considered if the requirements as a whole are agreeable to the tenant, if not possible, then it would become necessary again to consider other potential tenants. If possible, the lease agreement is drawn up and the property is handed over to the tenant. A simplified process flow diagram is shown in figure 3.

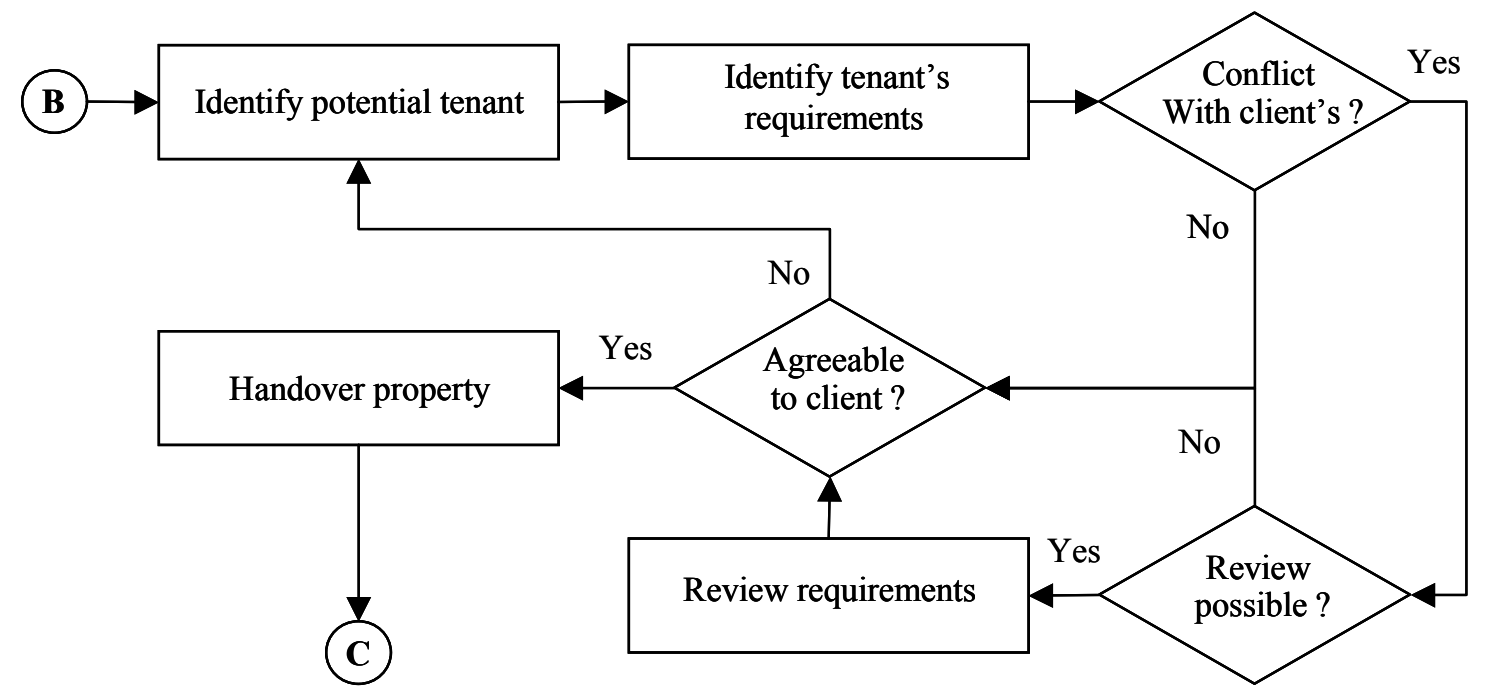

Figure 3: A simplified process flow diagram for the tenant selection phase.

\section{PIs Identification}

This phase is fairly straightforward and follows the tenant selection phase. The requirements as suitably identified from the previous phase become objectives that need to be converted to measurable terms. The property manager might need to include the facilities managers here, to give their opinions on the PIs development as they are going 
to be involved in measuring them, especially physical and functional indicators that reflect the day-to-day running of the property.

The phase therefore involves using the requirements to set out objectives for the property. The next step involves utilising these objectives to appropriately set out PIs under the categories highlighted under the requirements for the tenant and client respectively thus ensuring a balance of indicators. These include functional relating to tenants requirements other than functional, physical indicators, which would include statutory requirements, and financial indicators in the form of value and costs associated with the property. A check would be done to determine if PIs suitably represent the requirements. If they do not, the phase cycle is started again, if they do however, it becomes necessary to save these PIs in the property database and set targets, which take the process, flow to the next phase. The process flow diagram foe this phase is depicted in figure 4 .

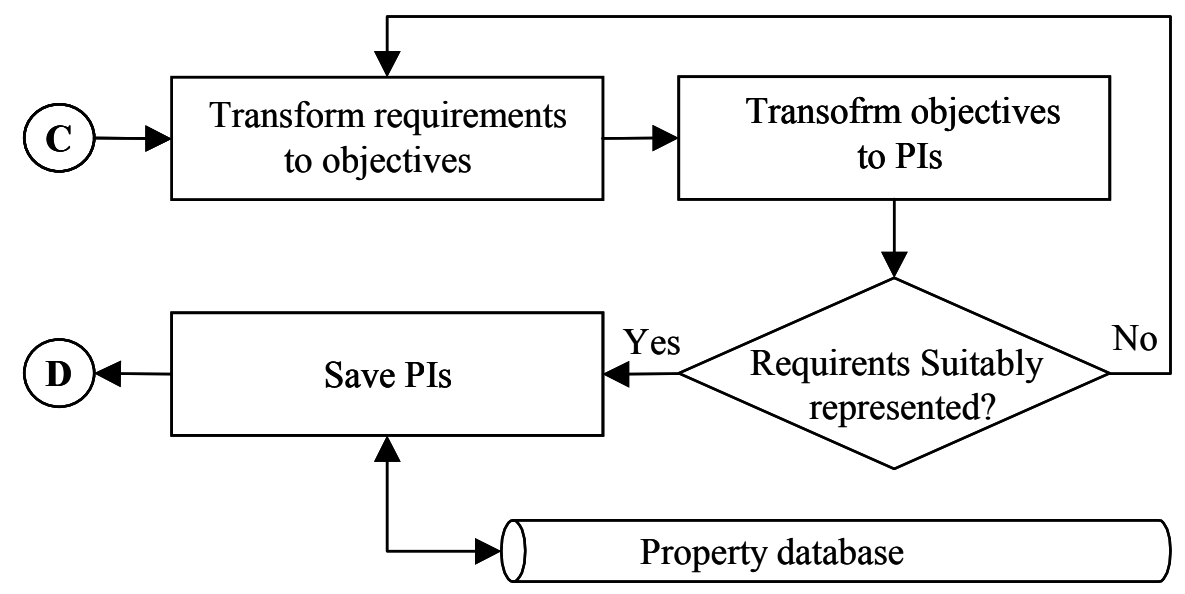

Figure 4: Process flow diagram for the PIs identification stage. 


\section{Targets Setting}

This phase involves setting targets for the PIs as identified in the previous phase. They stem from requirements stated by stakeholders in the form of the maximum acceptability implied in requirements, past performance of the property or/ and external benchmarks. The first step however involves assessing if past performance data is required to set targets. This might not be necessary in some instances, for example if general market conditions change in ways that would make the use of such targets unnecessary. Where these past performance data are to be used, it must first be ensured that such data are available, if they are available; the data from the property database are reviewed. If they are not available, it becomes necessary to assess if external benchmarks from other properties, or where possible, companies are relevant.

Where external benchmarks intended to be used as targets are lower than past performances, it might not be necessary to use them. If it is necessary to use them however, it will be essential to check if they are available. A review of the data gotten from the resource database and other external sources is necessary to convert them into targets using professional judgement. If none of these are available, the property manager will rely only on judgement. The targets are thus set and interval triggers at which they would be measured are also set and stored in the property database. These triggers might be lease expiration, statutory requirements, etc., to alert the property manager as to the need for a performance measurement exercise. The process flow diagram for this phase is depicted in figure 5. 


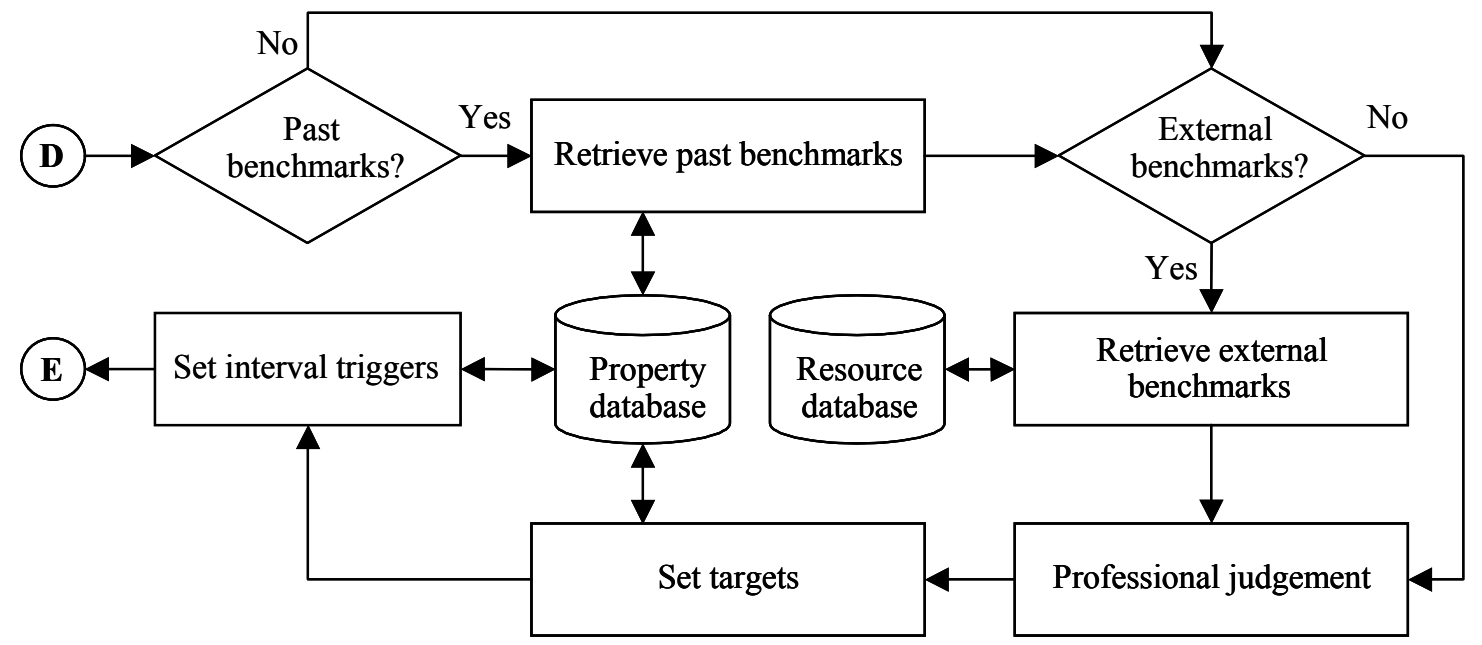

Figure 5: Process flow diagram for the targets setting stage.

\section{Performance Measurement}

This stage involves the actual measurement of various PIs according to triggers set in the previous stage. For physical indicators, a condition survey is arranged to check the physical structure as required. The methodology thus involves an identification of the physical indicators to be measured for that triggered interval or situation before selecting the appropriate equipment, times of inspection and setting out for the physical survey of the property. Any performance gaps are identified and it is further decided on whether it is necessary to carry out other performance measurements. It is recommended that inhouse facilities managers be allocated the actual measurements of physical and functional indicators since they are more involved in the day-to-day running of the property and have first-hand relations with tenants. For financial indicators, a cost review and a valuation of the property are proposed here. It is further enquired if other checks would be made to see if the tenant is on the property and has requested or complained about some of the requirements agreed upon not being met, which cannot be classified as physical or 
financial indicators. This phase basically encourages the grouping of performance interval measurement periods for the developed indicators. The next phase comprises of the carrying out of improvements if necessary. The Performance flow diagram for the measurement phase is shown in figure 6 .

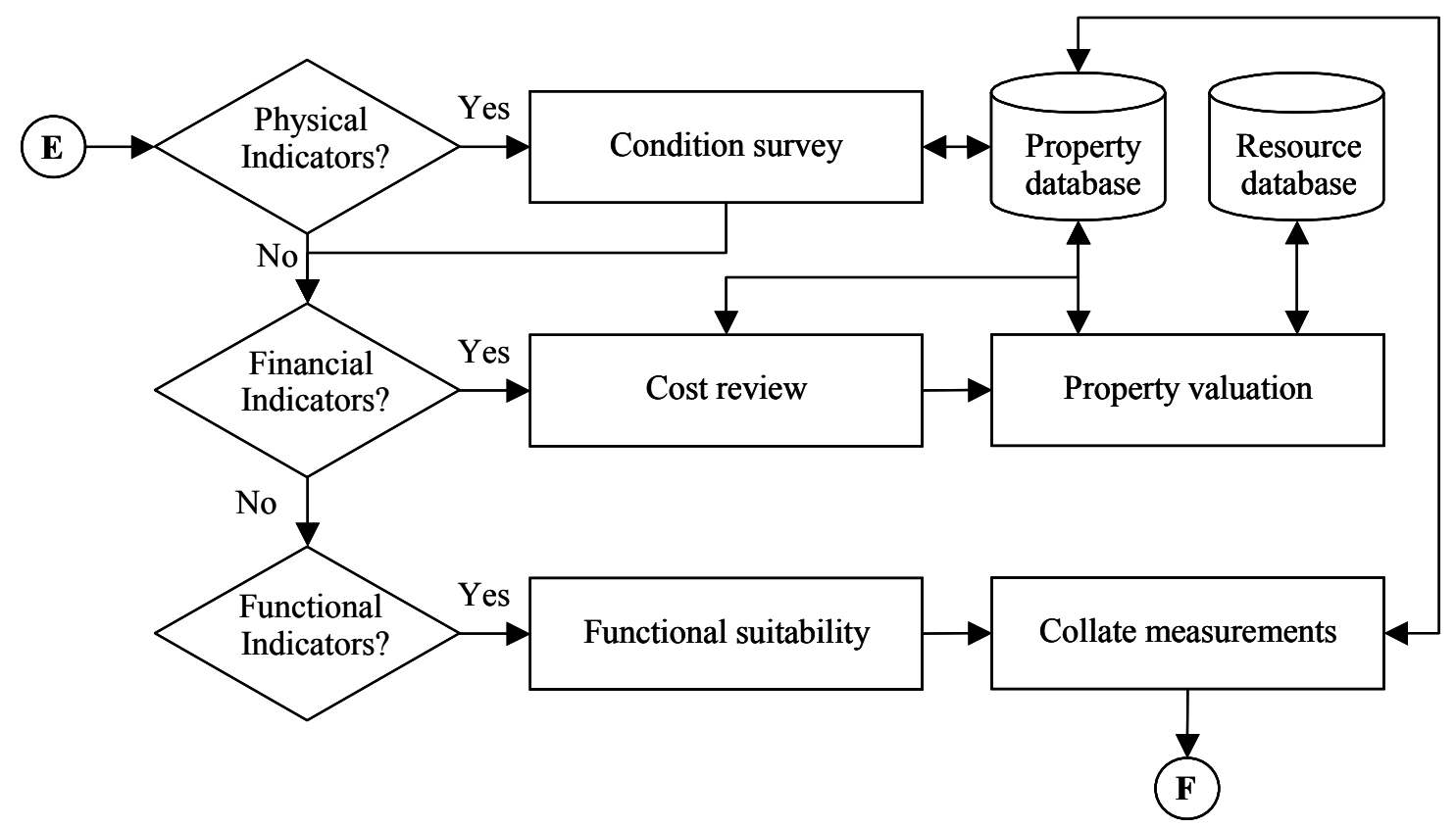

Figure 6: Process flow diagram for the performance measurement stage.

\section{Effect Improvements}

Following the logic of the performance measurement phase, any shortfalls in PIs measurement are identified and the causes of these shortfalls are investigated for the improvement process. Alternative improvement strategies are examined and a risk evaluation process is proposed here as this involves decision making in a bid to optimise benefits achievable from improvements. If this exercise indicates that improvement is not necessary, the process flow moves on to consider if the property is still under 
management, and if not, the process ends there. If however, improvement is necessary, alternatives should be chosen using appropriate methods of evaluation that would allow for financial and non-financial factors to be considered such as whole-life costing followed by further risk analysis. After any required improvements are effected, the property attributes are updated and performance data are stored in the database.

If the property is still under management, if it is not, the process is ended. Otherwise, it is further considered if the property is undergoing a new lease or lease renewal. If not, the target setting phase is revisited. If it is a new lease or lease renewal, new requirements need to be reconsidered so the process flows onto the Client's requirements identification phase. The process flow diagram for the improvement phase is shown in figure 7.

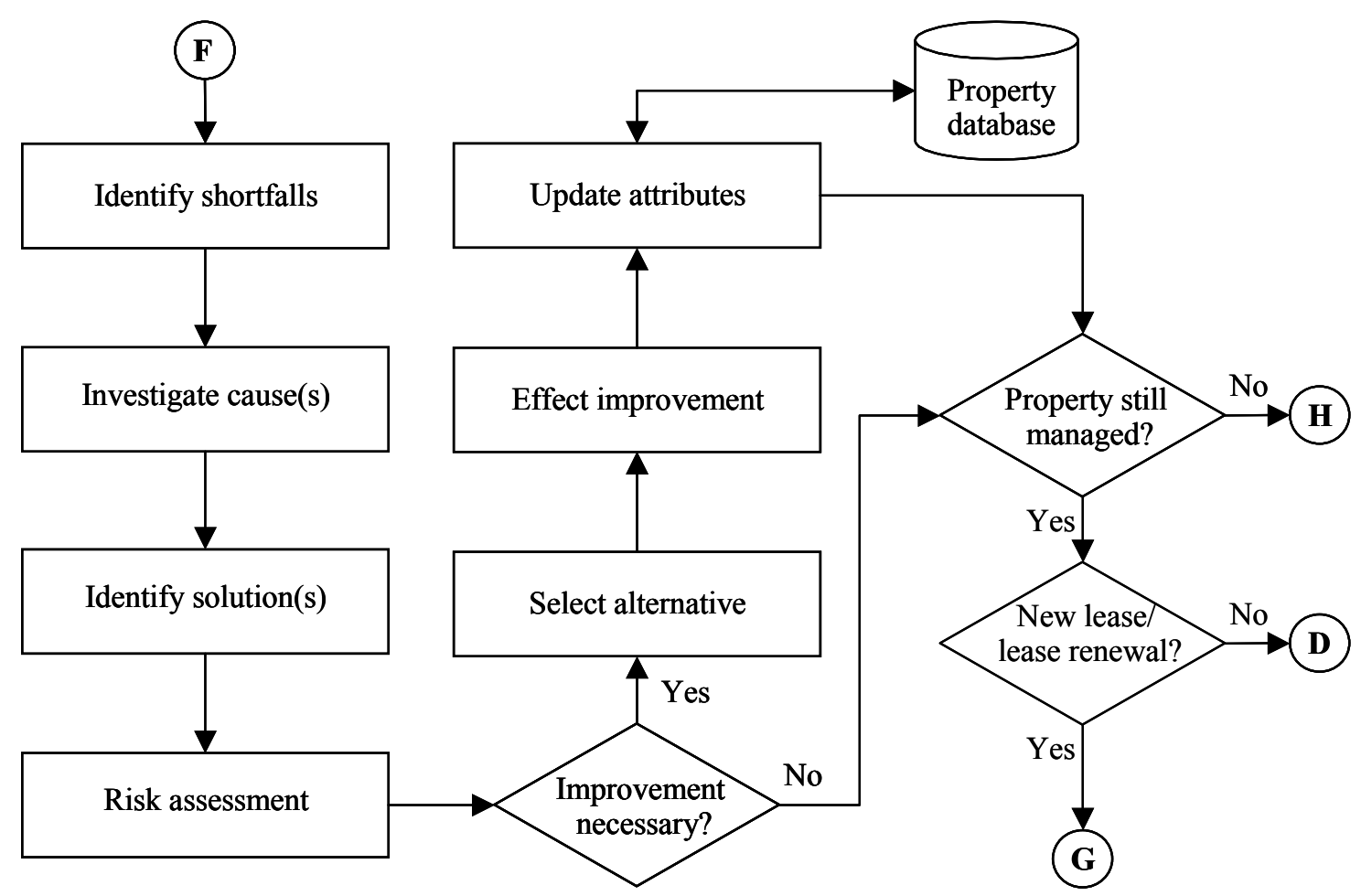

Figure 7: Process flow diagram for the improvement stage. 


\section{Complete Process Flow Diagram}

The process flow diagrams of individual phases would now be joined according to the framework in figure 1 to show the complete process flow diagram of the model as shown in figure 8.

\section{CONCLUSIONS}

Motivated by the lack of structured processes for carrying out the performance measurement of properties, a structured model for a performance assessment in property management has been developed. In the development of the model, performance measurement approaches and techniques have been integrated into property management processes and functions. First, Different views of general property management have been discussed and a line was effectively shown between facilities management and corporate real estate management, also classified as property management but not wholly for the purpose of this research. The study focused on property management for a client who leases out property. Then, key characteristics of effective performance assessment have been identified and transformed into implementation phases. Theses phases were arranged in logical order to form the framework of the model. The phases as identified included the identification of property attributes, tenant's selection, PIs identification, targets setting, performance measurement and effecting improvement as appropriate and a renewal of the process at appropriate stages. Each phase was subsequently discussed and appropriately represented in a process flowchart form. Finally, the complete process flow of the proposed model has been outlined by integrating individual phases' flowcharts. 


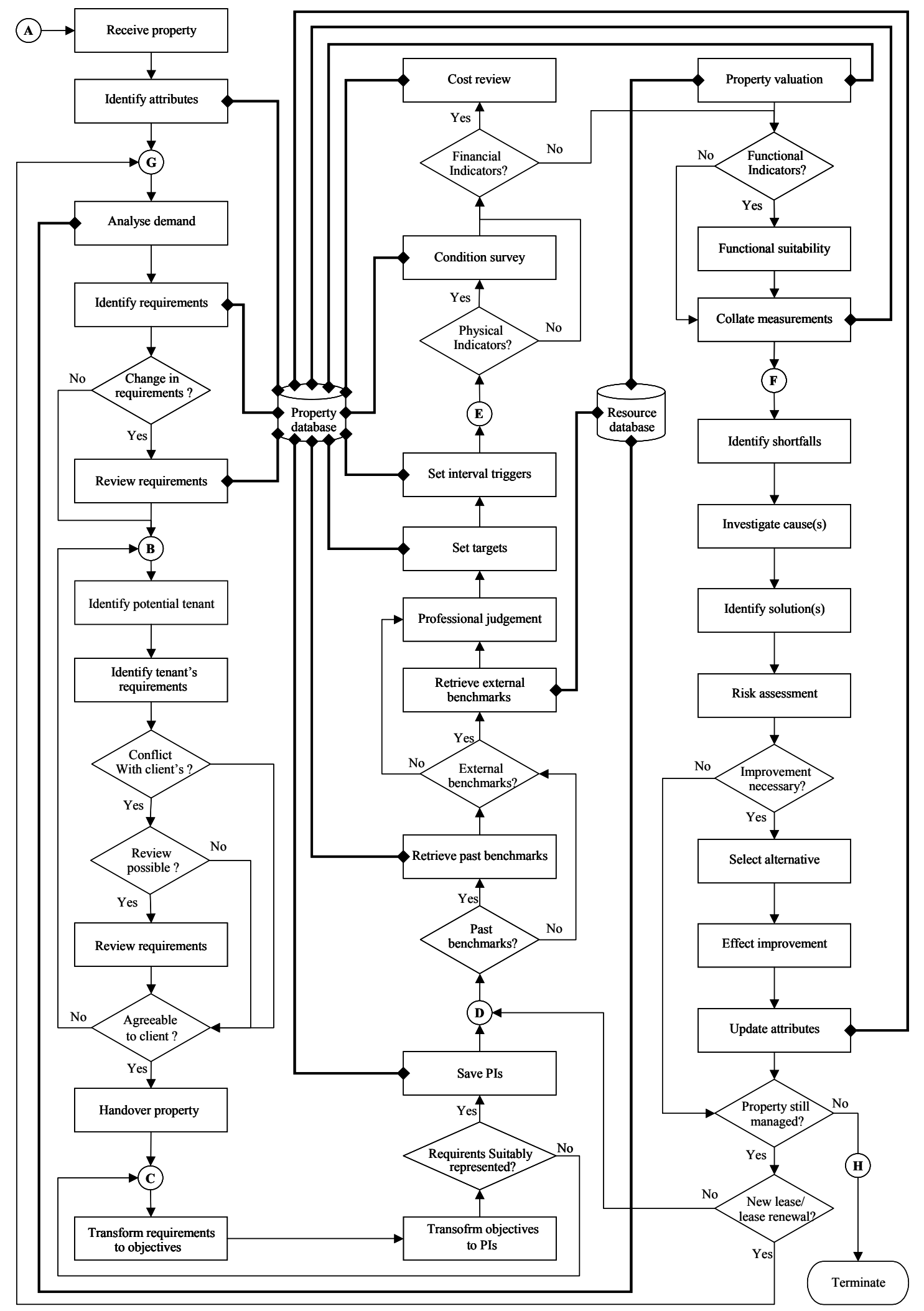

Figure 8: Complete process flow diagram of the model. 


\section{ACKNOWLEDGEMENT}

The third author would like to acknowledge the financial support of the Petroleum Technology Development Fund (PTDF), a body mandated by the Nigerian government to provide scholarships for the training of Nigerian graduates.

\section{REFERENCES}

Amaratunga, D (2000) Assessment of facilities management performance. Property, 18(4), 258-266.

Amaratunga, A and Baldry, D (2001) Case study methodology as a means of theory building: performance measurement in facilities management organisations. Work Study, 50(3), 95-104.

Atta, J A (2003) An investigation of performance measurement techniques in property management. Unpublished MSc Thesis, School of Engineering, The Robert Gordon University, Aberdeen.

Baird, G and Gray, J (1996) How to plan and conduct evaluations. In: Baird, G, Gray, J, Isaacs, N, Kernohan, D and McIndoe, G (eds) Building evaluation techniques. New York: McGraw-Hill Inc.

Becker, F (1989) Post occupancy evaluation: research paradigm or diagnostic tool. In: Preiser, W. (ed). Building Evaluation. New York: Plenum Press.

Bon, R, McMahan, J and Carder, P (1998) Property performance measurement: from theory to management practice. Facilities, 16(7/8), 208-214

Bourne, M and Bourne, P (2000) Understanding the Balanced Scorecard in a week. The Institute of Management. Hodder \& Stoughton Educational.

Davis, G and Szigeti, F (1996) Serviceability tools and methods: matching occupant requirements and facilities. In Baird, G, Gray, J, Isaacs, N, Kernohan, D, and McIndoe, G (eds). Building evaluation techniques. New York: McGraw-Hill Inc.

Dixon, R (1991) Management theory and practice. London: Butterworth-Heinemann.

Douglas, J (1996) Building performance and its relevance to facilities management. Facilities, 14(3/4), 23-32. 
Downs, J (1991) Principles of Real Estate Management. Chicago: Institute of Real Estate Management of the National Association of Realtors.

Greed, J, Heath, R, Steel, M and Wood S (2000) An essential guide to property management. England: Chandos Publishing Oxford Ltd.

Jonge, H and Gray, J (1996) The Real Estate Norm (REN). In: Baird, G., Gray, J., Isaacs, N., Kernohan, D and McIndoe, G (eds) Building evaluation techniques. New York: McGraw-Hill Inc.

Sanger, M (1998) Supporting the balanced scorecard. Facilities, 47(6), 197-200.

Scarrett, D (1995) Property asset management. $2^{\text {nd }}$ ed, London: E \& FN Spoon, Ltd.

Tay, L and Ooi, J T L (2001), Facilities management: a "Jack of all trades?". Facilities, 19(10), 357-362.

Stansall, P (1994) Managing the facilities-property interface. Facilities, 12(10), 6-10.

Varcoe, B (1996) Facilities performance measurement. Facilities, 14(10/11), 46-51

\section{APPENDIX: LIST OF SYMBOLS}

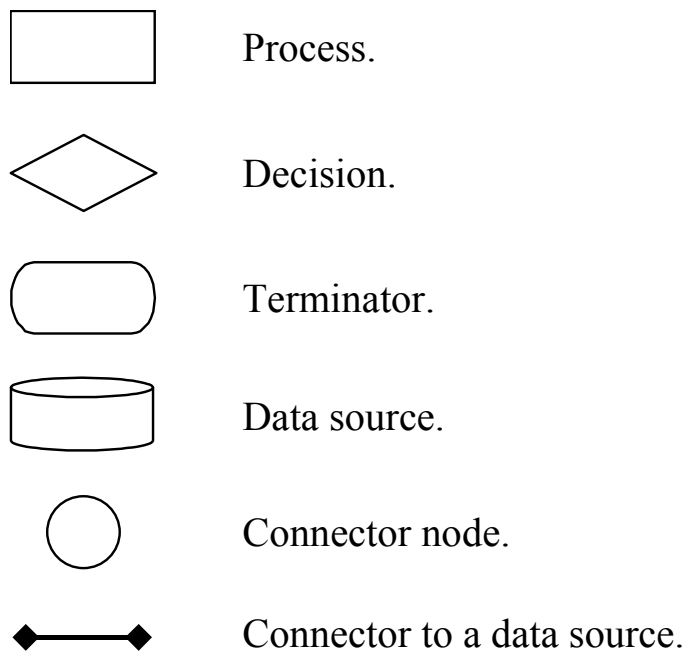

